\title{
STATIC ANALYSIS OF PORTAL AXLE OUTPUT SHAFT USING COMPOSITE MATERIAL
}

\author{
Bhaskar K ${ }^{1}$, Sanjay S.J. ${ }^{2}$, V.B.Math ${ }^{3}$

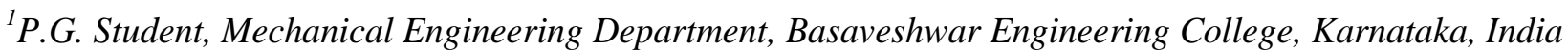 \\ ${ }^{2}$ Assistant Professor, Mechanical Engineering Department, Basaveshwar Engineering College, Karnataka, India \\ ${ }^{3}$ Professor, Mechanical Engineering Department, Basaveshwar Engineering College, Karnataka, India
}

\begin{abstract}
Portal axles (or portal gear) are an offroad technology where the axle tube is above the center of the wheel hub and where there is a reduction gearbox in the hub. It is the shaft which must tough and strong, since composite materials have promising properties, which can reduce the weight and almost equal to conventional material properties. In this paper portal axle shaft analyzed by Finite Element Analysis considering three different composite materials and varying parameters. i.e rib thickness and hollow shaft thickness are consider. Some of the parameters are kept constant they are depth of spokes, rib fillet radius, number of spokes. Torsional strength of the shaft compared for three different materials. When Rib Thickness are varied Deformation and Stresses are almost same for Kelvar/Epoxy and Boron/Epoxy materials but varied for E Glass/Polyester Resin. Similarly When Shaft Thickness is varied the results are same for Kelvar/Epoxy and Boron/Epoxy but varied for E Glass/Polyester Resin material.
\end{abstract}

Keywords: Portal axle, Composite Material, FEA.

\section{INTRODUCTION}

Portal axles are an offroad technology where the axle tube is above the center of the wheel hub as shown in figure1 and where there is a reduction gearbox in the hub. This gives two advantages ground clearance is increased, particularly beneath the low-slung differential housing of the main axles. Secondly the hub gearing allows the axle half shafts to drive the same power but at reduced torque. This reduces load on the axle crown wheel and differential. Front and rear axles are solid axles with portals, meaning the axle housings and the differentials center are located above the wheel's center. The gearing with its reduction, inside the portal housing, transfers the power to the wheel. Portals offer the most unique ground clearance as the axle and differential housing are lifted and not just the frame or chassis. Due to the gearing ratio inside the portal drop box, the stress on the whole driveline is significantly reduced as the full torque is only occurring at the wheel and subsequently reduced inside the portals.

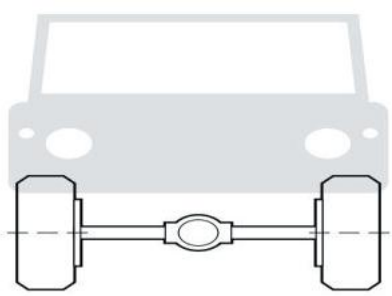

NORMAL AXLE

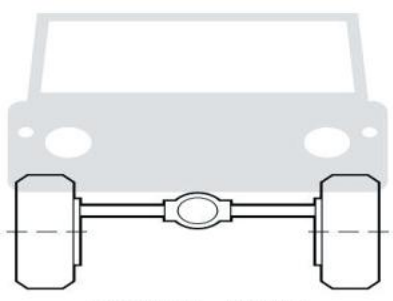

PORTAL AXLE
A parametric study for optimization of the output shaft of a portal axle is carried by Jong Boon et.al.[1], they have considered the Torsional Stress (Axial Stress) and Maximum Shear Stress. R.P.Kumar et.al.[2], conducted analysis of drive shaft with composite materials since composite materials are most widely used in design and various fields. The main objective of the work is to composite material are subjected to stress and deformation and they are compared with each other.

\section{ANALYTICAL METHOD}

Distortion energy theory is applied to determine the Von Mises stress of the hollow shaft[4]. Distortion Energy Theory also known as the Von Mises criterion postulates that failure is caused by the elastic energy associated with shear deformation. The hollow shaft is assumed to be ductile material, thus Distortion Energy Theory is valid and can be applied. Distortion Energy Theory considers the maximum axial stress in the transverse direction caused by the bending moment and the maximum shear stress caused by Torque. For a hollow shaft, the maximum axial stress is;

$$
\sigma_{x}=\frac{32 M D}{\pi\left(D^{4}-d^{4}\right)}
$$

Similarly, the maximum shear stress is[6]:

$$
\tau_{x v}=\frac{16 T D}{\pi\left(D^{4}-d^{4}\right)}
$$

Fig -1: Normal Axle and Portal Axle. 


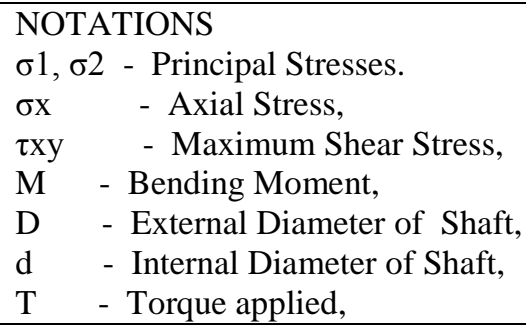

To calculate Von Mises stress, For plane stress condition $\sigma y=0$,

$$
\sigma_{1}, \sigma_{2}=\frac{16}{\pi d^{3}}\left(M \pm \sqrt{M^{2}+T^{2}}\right)
$$

In general case

$$
\sigma_{g}=\sqrt{\sigma_{1}^{2}-\sigma_{1} \sigma_{2}+\sigma_{2}^{2}}
$$

\section{COMPOSITE MATERIAL}

A composite material can be defined as a combination of two or more materials that results in better properties than those of the individual components used alone. In contrast to metallic alloys, each material retains its separate chemical, physical, and mechanical properties. The two constituents are reinforcement and a matrix. The main advantages of composite materials are their high strength and stiffness, combined with low density, when compared with bulk materials, allowing for a weight reduction in the finished part. Matrix phase The primary phase, having a continuous character, is called matrix. Matrix is usually more ductile and less hard phase. It holds the dispersed phase and shares a load with it[5].

\section{MATERIAL PROPERTIES}

Table -1: Material Properties of Composite Materials

\begin{tabular}{|l|l|l|l|l|l|}
\hline $\begin{array}{l}\text { Sl. } \\
\text { no }\end{array}$ & Properties & $\begin{array}{l}\text { Steel } \\
\text { (SM4 } \\
\text { 5C) }\end{array}$ & $\begin{array}{l}\text { Kevlar } \\
\text { /Epoxy }\end{array}$ & $\begin{array}{l}\text { Boron } \\
\text { /Epoxy }\end{array}$ & $\begin{array}{l}\text { E-glass } \\
\text { /Polyest } \\
\text { er Resin }\end{array}$ \\
\hline 1 & $\begin{array}{l}\text { E X } \\
\text { direction } \\
\text { (Pa) }\end{array}$ & $\begin{array}{l}2.07 \\
\text { e11 }\end{array}$ & $\begin{array}{l}95.71 \\
\text { e9 }\end{array}$ & $\begin{array}{l}281.86 \mathrm{e} \\
9\end{array}$ & $\begin{array}{l}3.4 \\
\text { e10 }\end{array}$ \\
\hline 2 & $\begin{array}{l}\text { E Y } \\
\text { direction } \\
(\mathrm{Pa})\end{array}$ & - & $10.45 \mathrm{e} 9$ & $\begin{array}{l}10.88 \\
\mathrm{e} 9\end{array}$ & $\begin{array}{l}6.53 \\
\mathrm{e} 9\end{array}$ \\
\hline 3 & $\begin{array}{l}\text { E Z } \\
\text { direction } \\
(\mathrm{Pa})\end{array}$ & - & $10.45 \mathrm{e} 9$ & $\begin{array}{l}10.88 \\
\mathrm{e} 9\end{array}$ & $6.3 \mathrm{e} 9$ \\
\hline 4 & $\begin{array}{l}\text { Major v } \\
\text { XY }\end{array}$ & 0.3 & 0.34 & 0.2451 & 0.217 \\
\hline
\end{tabular}

\begin{tabular}{|l|l|l|l|l|l|}
\hline 5 & $\begin{array}{l}\text { Major v } \\
\text { YZ }\end{array}$ & - & 0.37 & 0.0095 & 0.366 \\
\hline 6 & $\begin{array}{l}\text { Major v } \\
\text { XZ }\end{array}$ & - & 0.34 & 0.2451 & 0.217 \\
\hline 7 & $\begin{array}{l}\tau \text { Modulus } \\
\text { XY (pa) }\end{array}$ & - & $25.08 \mathrm{e} 9$ & $67.49 \mathrm{e} 9$ & $\begin{array}{l}2.433 \\
\mathrm{e} 9\end{array}$ \\
\hline 8 & $\begin{array}{l}\tau \text { Modulus } \\
\text { YZ (pa) }\end{array}$ & - & $25.08 \mathrm{e} 9$ & $67.49 \mathrm{e} 9$ & $\begin{array}{l}1.698 \\
\mathrm{e} 9\end{array}$ \\
\hline 9 & $\begin{array}{l}\tau \text { Modulus } \\
\text { XZ (pa) }\end{array}$ & - & $25.08 \mathrm{e} 9$ & $67.49 \mathrm{e} 9$ & $\begin{array}{l}2.433 \\
\mathrm{e} 9\end{array}$ \\
\hline 10 & $\begin{array}{l}\text { Density } \\
(\mathrm{Kg} / \mathrm{m} 3)\end{array}$ & 7600 & 1402 & 2249 & 2100 \\
\hline
\end{tabular}

\section{MODELING OF SHAFT WITH RIB}

A Hollow Shaft with Rib is modeled using CAD software.

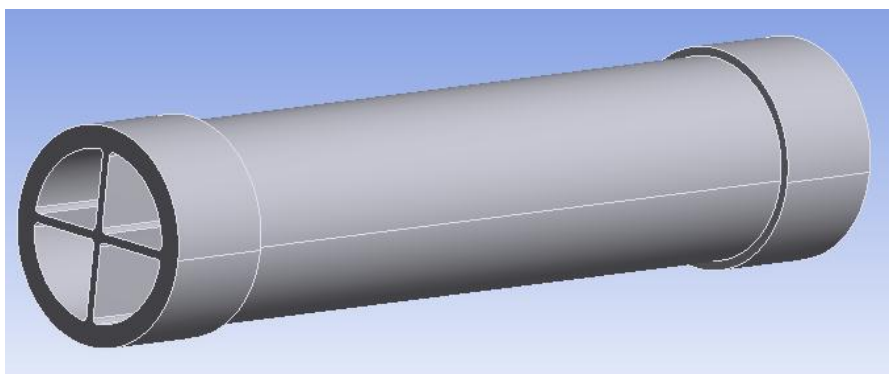

Fig -2: Hollow Shaft For Case 1

In Case $1:$ Number of Spokes, Rib Fillet Radius, Depth of the Spokes, Rib Thickness are Constant i.e No. of spokes $=4$, Rib Fillet Radius $=1 \mathrm{~mm}$, Depth of the Spokes $=25 \mathrm{~mm}$, Rib Thickness $=2 \mathrm{~mm}$ and Hollow Shaft Thickness is varied from $1 \mathrm{~mm}$ up to $5 \mathrm{~mm}$.

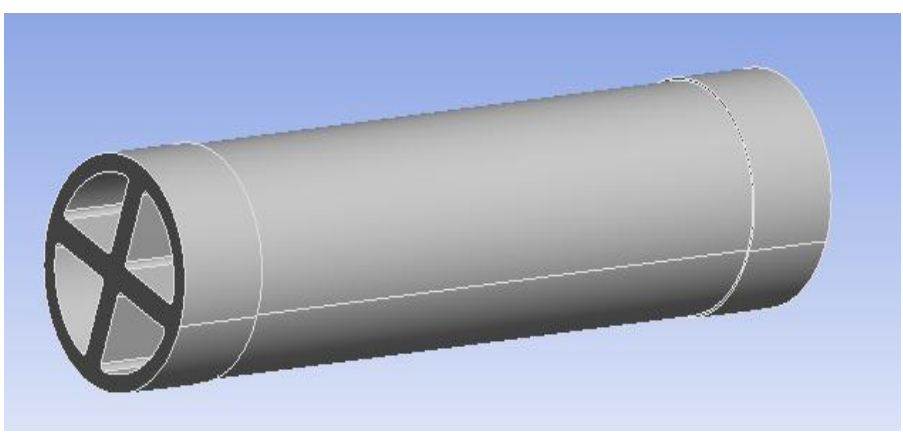

Fig -3: Hollow Shaft For Case 2 
In Case 2 : Number of Spokes, Rib Fillet Radius, Depth of the Spokes, Rib Thickness are Constant i.e No. of spokes $=4$, Rib Fillet Radius $=1 \mathrm{~mm}$, Depth of the Spokes $=25 \mathrm{~mm}$, Hollow shaft thickness $=4 \mathrm{~mm}$ and Rib Thickness is varied from $1 \mathrm{~mm}$ up to $5 \mathrm{~mm}$. Toatl length of Shaft $210 \mathrm{~mm}$, Dia of shaft $37 \mathrm{~mm}$.

\section{FINITE ELEMENT ANALYSIS}

In mathematics, the finite element method (FEM) is a numerical technique for finding approximate solutions to boundary value problems for differential equations. It uses variational methods (the calculus of variations) to minimize an error function and produce a stable solution. Analogous to the idea that connecting many tiny straight lines can approximate a larger circle, finite element method encompasses all the methods for connecting many simple element equations over many small subdomains, named finite elements, to approximate a more complex equation over a larger domain[7].

\subsection{Loads and Boundary Condition}

Shaft is a component which is subjected to various types of loads like Force, Moment, Torque etc. In the present paper shaft is fixed at one end and subjected to Torque of $100 \mathrm{~N}-\mathrm{m}$.

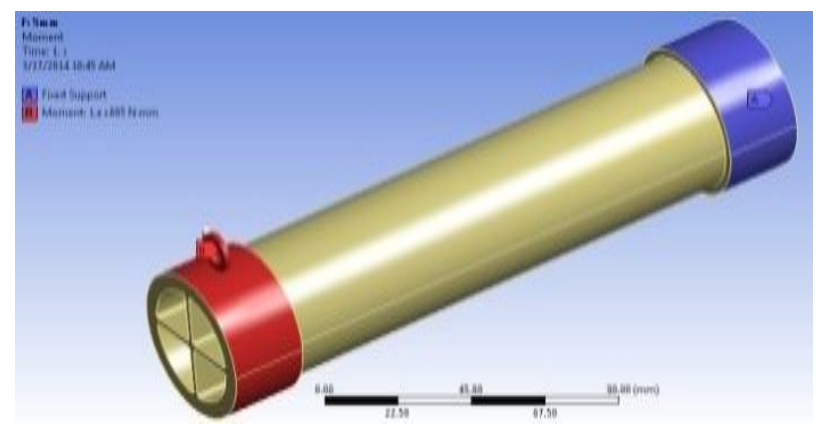

Fig -4: Fix support and Moment for Case 1

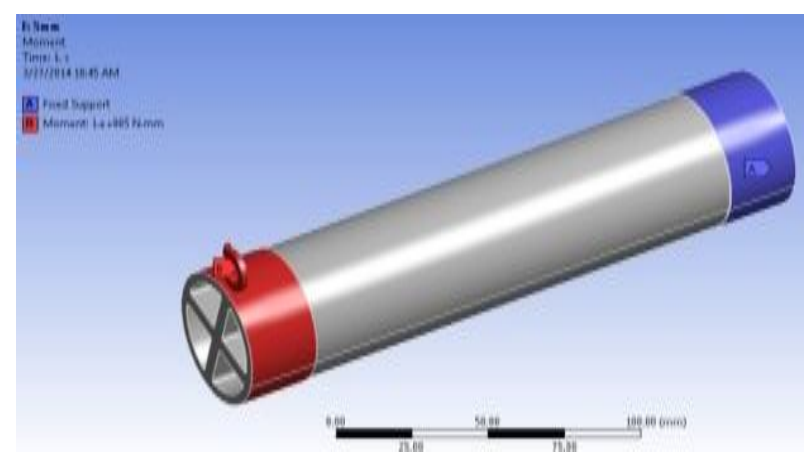

Fig -5: Fix support and Moment for Case 2

Figure 4 and 5 shows components for case 1 and case2. In case1 rib thickness is $2 \mathrm{~mm}$ but shaft thickness varied and one end of the shaft in fixed other end is applied with Torque of
$100 \mathrm{~N}-\mathrm{m}$. In case 2 shaft thickness is $4 \mathrm{~mm}$ and rib thickness is varied and one end of the shaft is fixed other end is applied with Torque of $100 \mathrm{~N}-\mathrm{m}$.

\section{RESULTS AND DISCUSSION}

\subsection{For Case 1:}

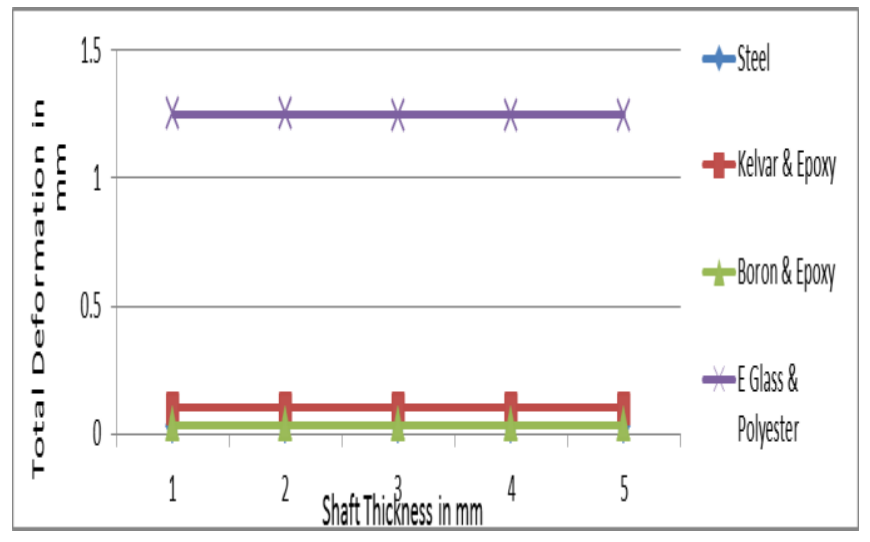

Fig -6: Total Deformation Vs Rib Thickness

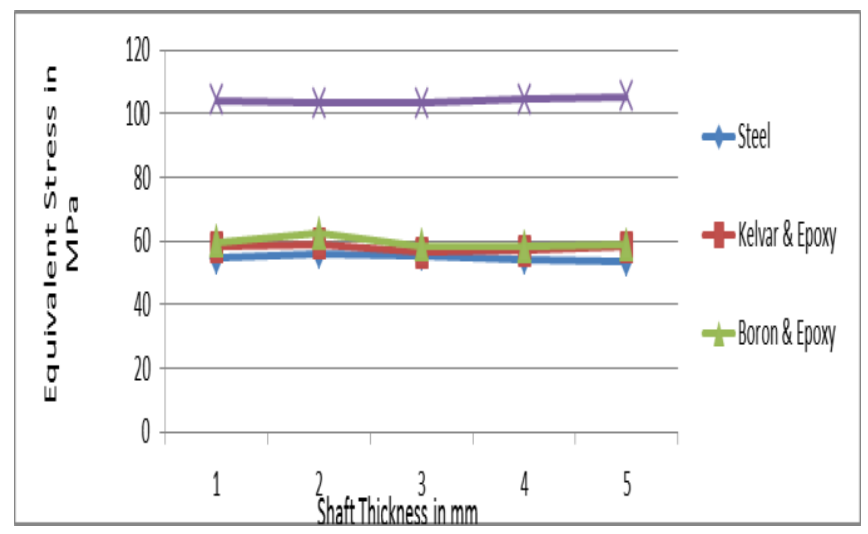

Fig -7: Equivalent Stress Vs Rib Thickness

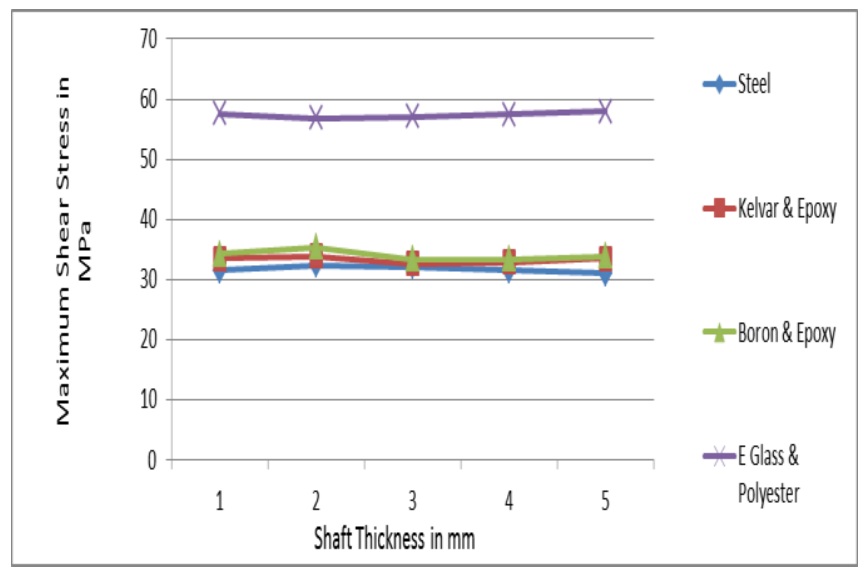

Fig -8: Maximum Shear Stress Vs Rib Thickness 
From figure 6 to 8 for case 1shows graph of total deformation vs varying rib thickness, equivalent stress vs varying rib thickness and maximum shear stress vs varying rib thickness and comparison is made for conventional material and composite materials.

\subsection{For Case 2:}

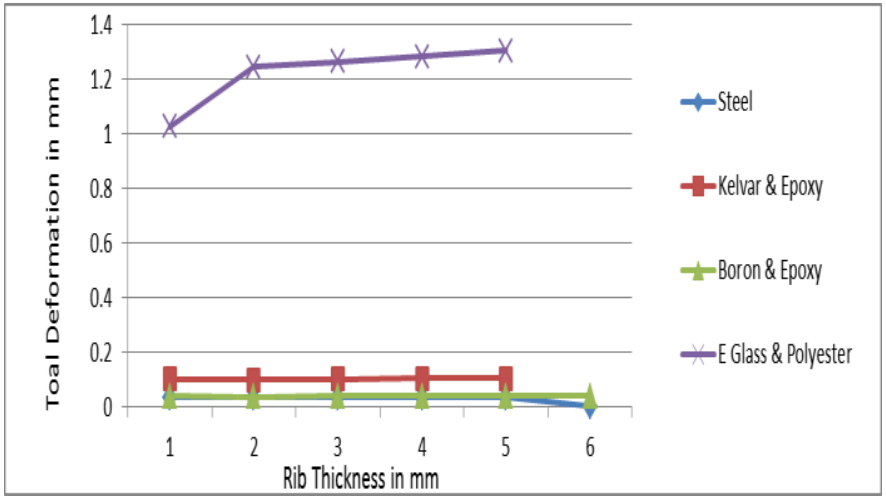

Fig -9: Total Deformation Vs Shaft Thickness

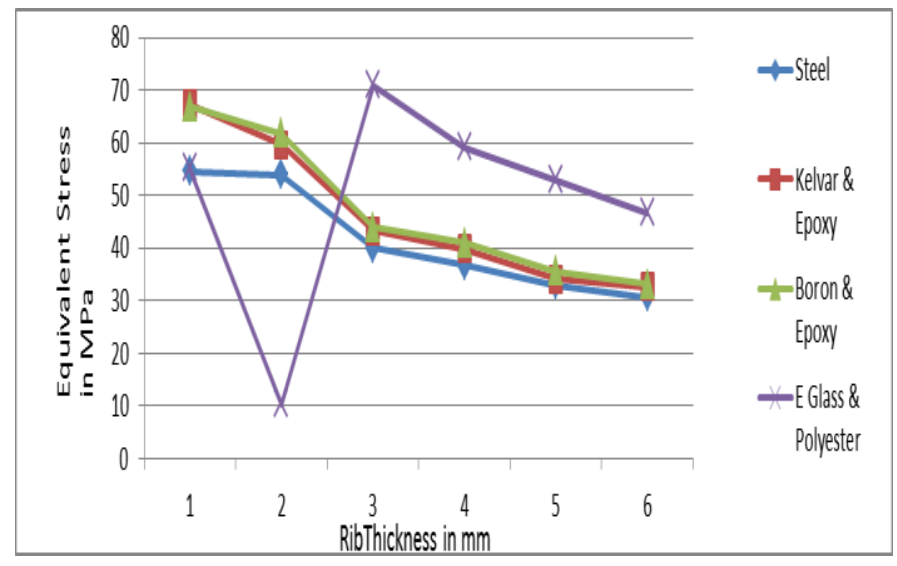

Fig -10: Equivalent Stress Vs Shaft Thickness

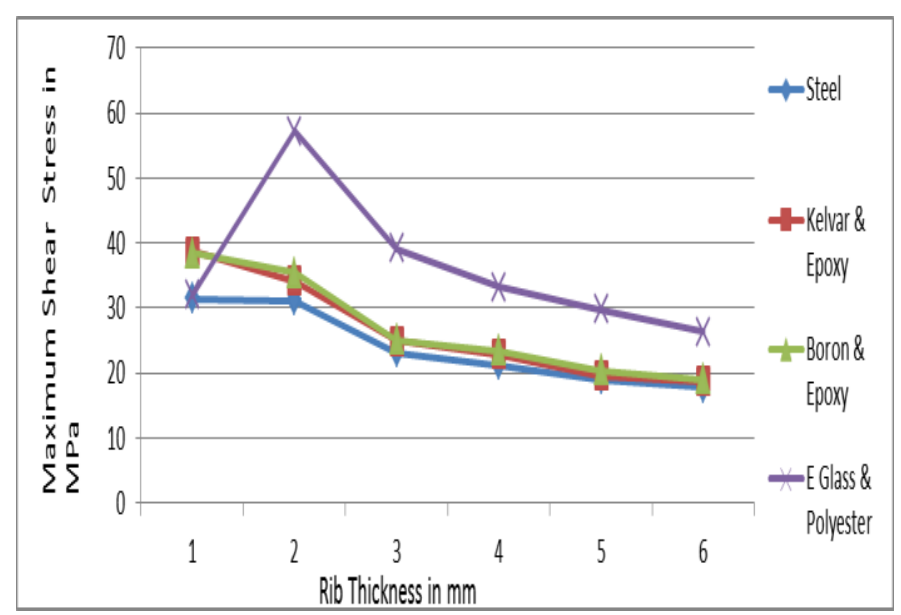

Fig-11: Maximum Shear Stress Vs Shaft Thickness
From figure 9 to 11 for case 2 shows graph of total deformation vs varying rib thickness, equivalent stress vs varying rib thickness and maximum shear stress vs varying rib thickness and comparison is made for conventional material and composite materials.

\section{CONCLUSIONS}

From this study the following conclusion can be drawn,

- Total deformation and Equivalent Stress of conventional material (Steel) and Kelvar/Epoxy, Boron/Epoxy are within the acceptable range for both the cases.

- Maximum Shear Stress of conventional material (Steel) and Kelvar/Epoxy, Boron/Epoxy are within the acceptable range for both the cases.

- E Glass/Epoxy material is not within the acceptable range for Total deformation, Equivalent Stress and Maximum Shear Stress.

If at all change in parameters of the component is considered, The affect the stress value as well as deformation value for composite materials will not change so, composite materials like Kelvar/Epoxy and Boron/Epoxy are accepted as replacement materials for shaft like this case.

\section{ACKNOWLEDGEMENTS}

I take this opportunity to express my gratitude to my guide Prof.Sanjay.S.J and Dr.V.B.Math for their kind co-operation during this period. Their constant motivation enabled me to widen the horizon of my paper work and interest.

\section{REFERENCES}

[1]. Joung Boon Ooi, Xin Wang, Ying Pio Lin et.al.(2013), "Parametric Optimization of the Output Shaft of a Portal Axle using Finite Element Analysis", Journal of Engineering.59(2013)10,613-619.

[2]. R.P.Kumar Rompicharla, Dr.K.Rambabu (2012)."Design and Analysis of Drive Shaft with Composite Materials", Research Expo International Multidisciplinary Research JournalVolume - II , Issue - II.

[3]. Xu, X.L., Yu, Z.W., Ding, H.X. (2006). "Failure analysis of a diesel engine gear-shaft", Engineering Failure Analysis, vol. 13, no. 8, p. 1351-1357.

[4]. Shigley, J.E., Mischke, C.R. (1989). Mechanical Engineering Design, 5th ed.McGraw Hill Publication, New York.

[5]. ASHBY M.F.(1998). Engineering Material,2nd ed, Bodmill Publication, Cornwall.

[6]. Dr. Sadhu Singh.(2011). Theory of Elasticity, 6th ed.Sudha Publication, India.

[7]. Saeed M.Finite Element Analysis Theory and Application.

[8]. ANSYS user manual 2014.

[9]. CATIA user manual V5R20. 